\title{
Cell Life on the Surface of Lens Implants*
}

\author{
J. Reimer Wolter \\ The Departments of Ophthalmology and Pathology of the University of Michigan Medical Center, Ann Arbor, Michigan, USA
}

\begin{abstract}
A simple technique called lens implant cytology is used to demonstrate cellular membranes on three plastic intraocular lenses removed at about 1,2 and 3 years after implantation. The pattern of the reactive process somewhat resembles a special foreign body reaction. The cells living on the lens surface have successfully formed a separating membrane between implants and the remainder of the eye in all three cases.
\end{abstract}

Zusammenfassung. Eine einfache Methode, Linsenimplant Zytologie genannt, wurde benutzt, um zellige Membranen auf drei Plastiklinsen darzustellen, die 1, 2 und 3 Jahre nach Einpflanzung entfernt wurden. Der beobachtete reaktive Prozeß ist einer besonderen Fremdkörperreaktion ähnlich. Die Zellen auf der Linsenoberfläche haben in allen drei Fällen mit Erfolg eine trennende Schicht zwischen Plastiklinse und innerem Auge geschaffen.

\footnotetext{
* Supported by The Research To Prevent Blindness, Inc., New York, N.Y.
}

Offprint requests to: J. Reimer Wolter, M.D., Department of Ophthalmology, University of Michigan Medical Center, Ann Arbor, Michigan 48109, USA
Living tissues have a usually very effective way of dealing with foreign substances. This so-called foreign-body reaction has three components. The first is an acute inflammatory response involving polymorph nuclear leucocytes. The second is more chronic and involves cells, that also come from the blood stream: the histiocytes. These free moving cells have the ability to phagocytise small particles, digest these or deliver them back to blood vessels [1]. When histiocytes find large pieces of foreign substance, they first form a continuous cell wall around them for separation. In this process the histiocytes enlarge and change into so-called epithelioid cells. When the foreign substance persists, the epithelioid cells form the large protoplasmic units with numerous nuclei known as giant cells. The aim of these large cells is to surround and contain even large or multiple foreign bodies in their protoplasm. The third component of a typical foreign body reaction is a fibroblastic response. The fibroblasts are mobilized from the local mesoderm. They surround the foreign substance as well as the accumulated histiocytes and soon start to form collagen with the aim to build a firm capsule. Thus, foreign substances, that cannot be phagocytised and carried away by histiocytes, will first be surrounded by histiocytes and later firmly encapsulated by. fibrous tissue. In the process

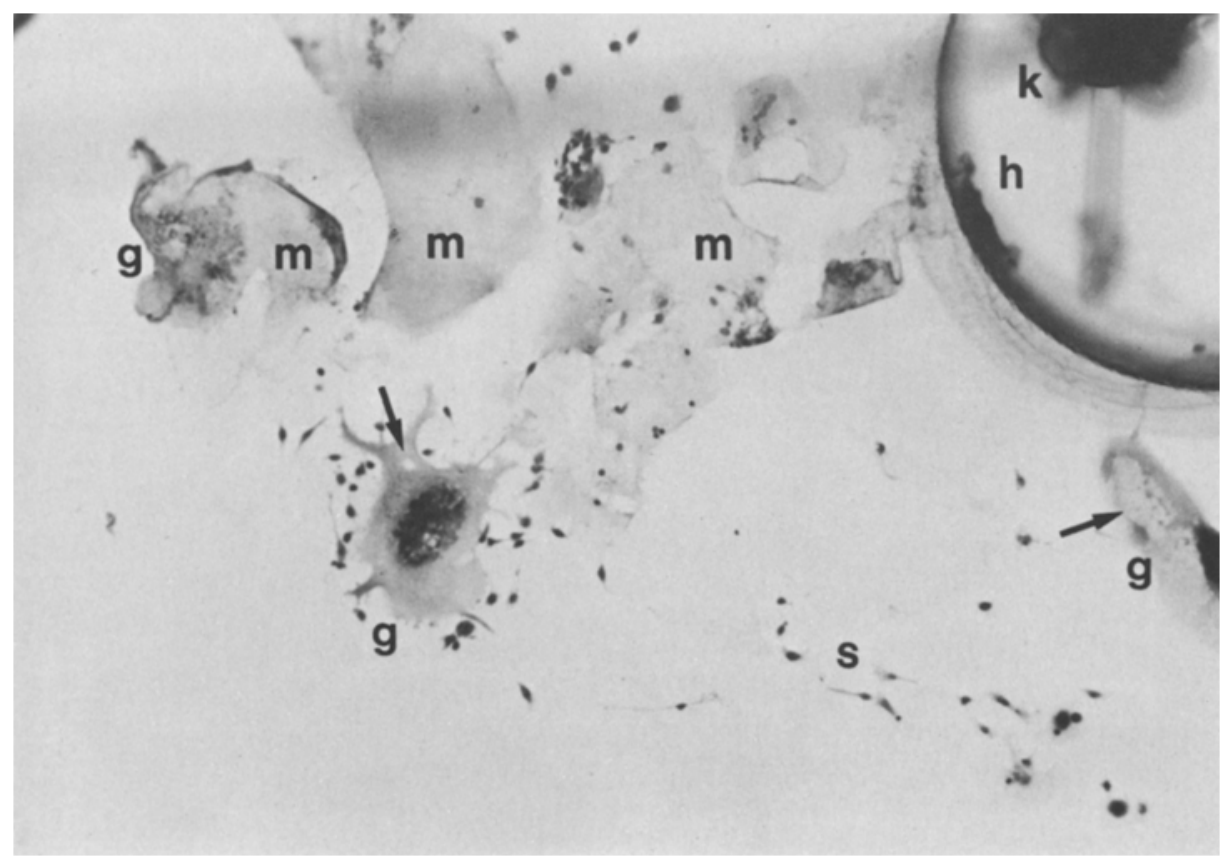

Fig. 1. First implant with membrane fragments $(m)$ on its posterior surface next to a hole $(h)$ containing the knot of the iris suture $(k)$. The membrane contains large giant cells $(g)$ with protoplasmic vacuoles (arrows). Groups of fibroblast-like small cells $(s)$ are seen in the interspaces. - Whole implant cytology technique, $\mathrm{H}$ and $\mathrm{E}$ stain, photomicrograph $\times 37,5$ 


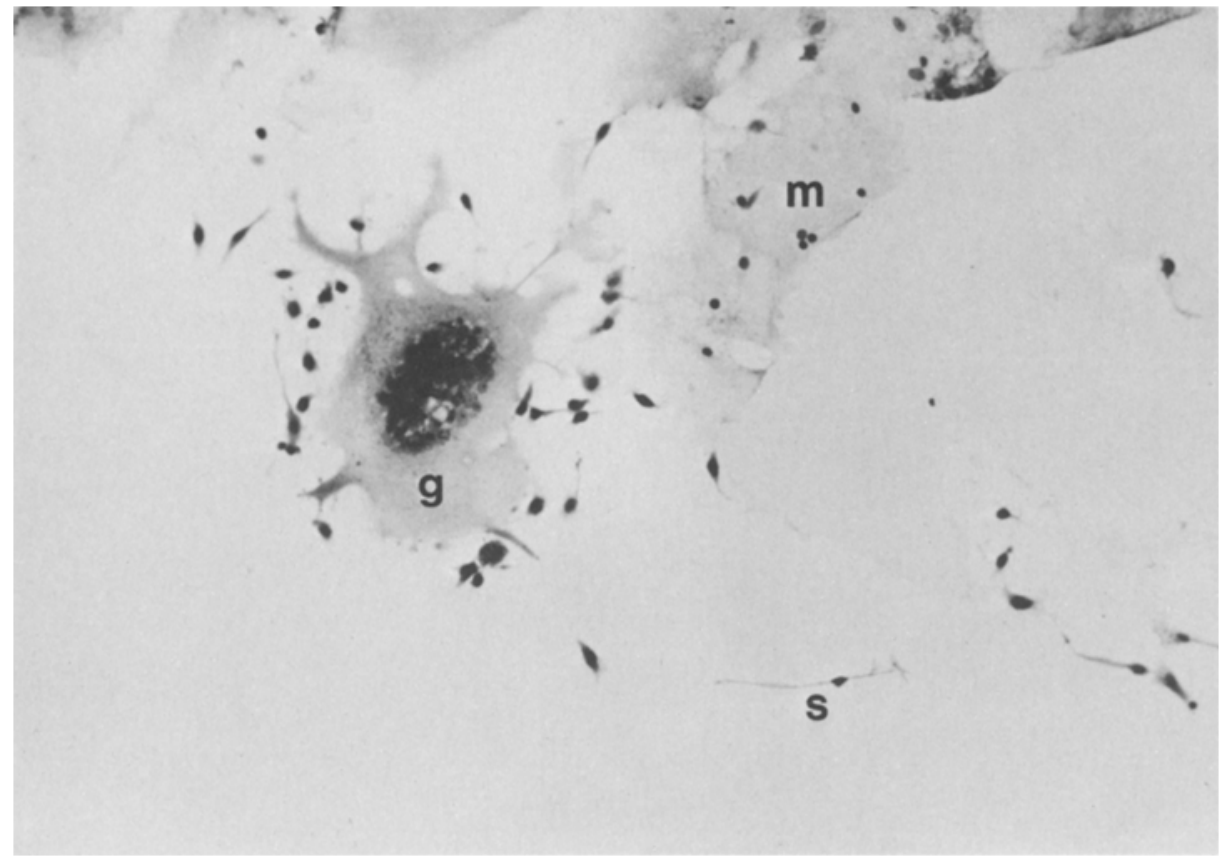

Fig. 2. First implant, higher power of foreign body giant cell $(g)$ and small fibroblast-like cells $(s)$ seen in Fig. 1. Folding and overlapping of fragmented membrane $(m)$ explains darker areas. Whole implant cytology technique, $\mathrm{H}$ and $\mathrm{E}$ stain, photomicrograph $\times 90$

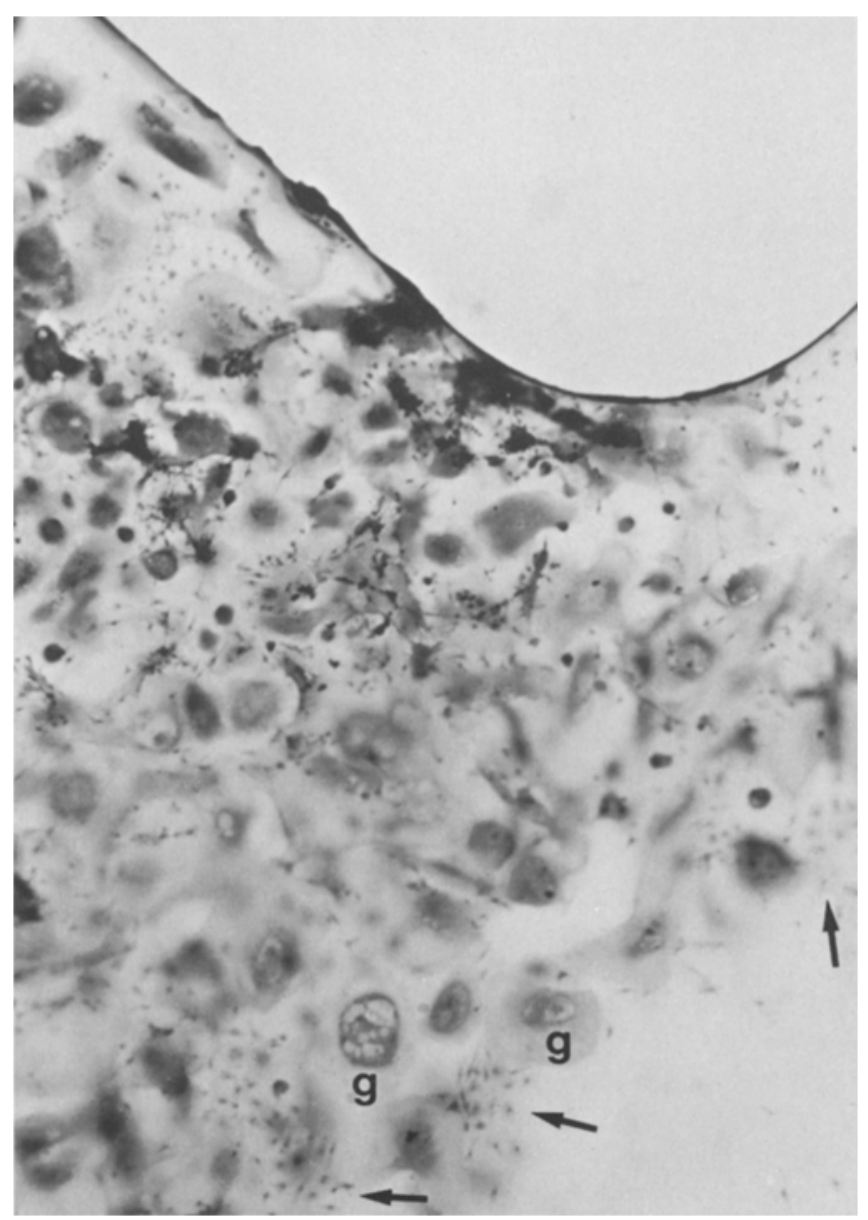

Fig. 3. Second implant at the junction of the two superior footplates. Large giant cells $(\mathrm{g})$ cover most of the lens surface and groups of numerous small fibroblast-like cells are seen in the membrane in the interspaces between the large cells (arrows). - Whole implant cytology technique, $\mathrm{H}$ and $\mathrm{E}$ stain, photomicrograph $\times 37,5$ of healing, the fibrous capsule shrinks like a scar and conforms to the size and shape of the foreign body. Most of the histiocytes disappear and the fibrous capsule takes care of the permanent isolation of the foreign substance. Steroid medication is effective in suppressing or attenuating foreign body reaction.

Most of us have believed, that implantation of plastic lenses was not foreseen in the development of the defense systems of the human eye. Medicine, in principle, often is considered the art of outwitting nature, of course, and lens implantation has served as a good example for this. However, nature does not give up easily and evidence, that she knows very well, how to deal with these lenses, is accumulating. This is good news, indeed, since more extensive reactions may develop within the eye, when the first line of defense is overcome. It is the aim of the present paper, to show that foreign body reaction is not absent, when a lens implant is placed in the eye. There is new evidence to show, that its typical phases take place and the component cells make their appearance on the plastic lens at least in some cases. Knowledge of this cell reaction to lens implants in the human eye is an important detail, that will be helpful for the treatment of complications with the presently implanted lenses and for future improvements in lens implants and implantation techniques.

\section{Cytological Study}

This eye of a 60 year-old white male, who had suffered sudden death, was donated to the Eye Bank Program about 2 years after intracapsular cataract extraction and successful implantation of a two-loop medalion lens. The lens implant was removed from the eye after formalin fixation and the whole-implant cytology stain [2] was used. Fragments of a thin membrane were found on the lens surface (Fig. 1). These fragments quite obviously were parts of a more extensive membrane, that had covered the lens. However, most of the membrane was lost in the process of the removal of the implant from the eye. The membrane fragments stained very slightly with Eosin. They contained large giant cells with accumulations of multiple nuclei 

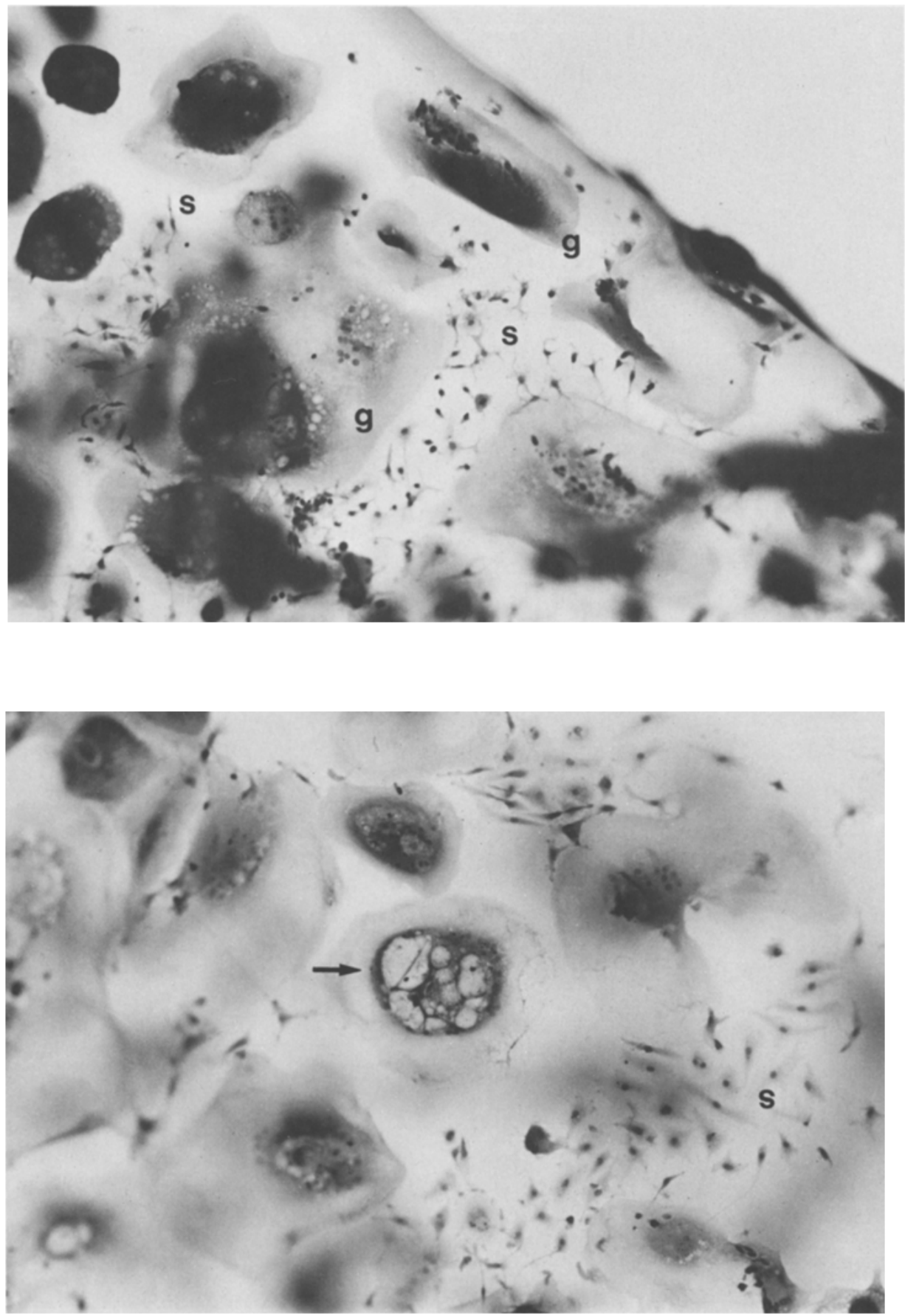

Fig. 4. Second implant, higher power of border of footplate with giant cells $(g)$ containing protoplasmic vacuoles indicating phagocytosis in many cells. The cellular membrane is seen to go around the edge of the implant. It contains groups of fibroblast-like small cells (s) in the spaces between giant cells. - Whole implant cytology technique, $\mathrm{H}$ and $\mathrm{E}$ stain, photomicrograph $\times 75$
Fig. 5. Second implant with a membrane containing large giant cells and groups of small fibroblast-like cells $(s)$ on the anterior surface of its optical zone. Distinct vacuoles are seen in the nuclear zone of some of the giant cells (arrow). - Whole implant cytology technique, $\mathrm{H}$ and $\mathrm{E}$ stain, photomicrograph $\times 90$ in the center (Figs. 1 and 2). These cells had an extensive protoplasm spread out on the surface of the implant. The protoplasm contained vacuoles indicating phagocytic activity (Figs. 1 and 2). Numerous small cells with oval nuclei and long branching processes were also contained in the membrane in the interspaces between the giant cells (Fig. 2). These small cells had the appearance of active fibroblasts, but some of them had some pigment granules in their protoplasm.

The same staining technique was used on a Choyce anterior chamber lens, that I removed from the eye of an 86 year-old white female 14 months after implantation because of subluxation with hypotony, papilledema and cystoid macular edema. This lens implant was clinically clear except for some spotty whitish deposits, that were visible only with the slit lamp micro- scope. Cytological study revealed a continuous membrane with many cells covering the whole implant (Figs. 3-7). In the intercellular spaces the membrane was slightly eosinophilic again and it showed occasional delicate wrinkles and defects, which were considered artifacts. The largest cells on the surface of this implant were giant cells with great numbers of centrally located nuclei (Figs. 3-7). Their protoplasm contained illdefined vacuoles (Figs. 5-7). Some of the giant cells also had more distinct vacuoles in the central nuclear zone (Fig. 4). Small cells with oval nuclei and branching processes were found in great numbers in the interspaces between the giant cells within the membrane covering the implant (Figs. 4-7). These small cells extended with their processes into the zones covered by giant cells only in rare instances (Fig. 6). Again, scarce pigment granules were seen 

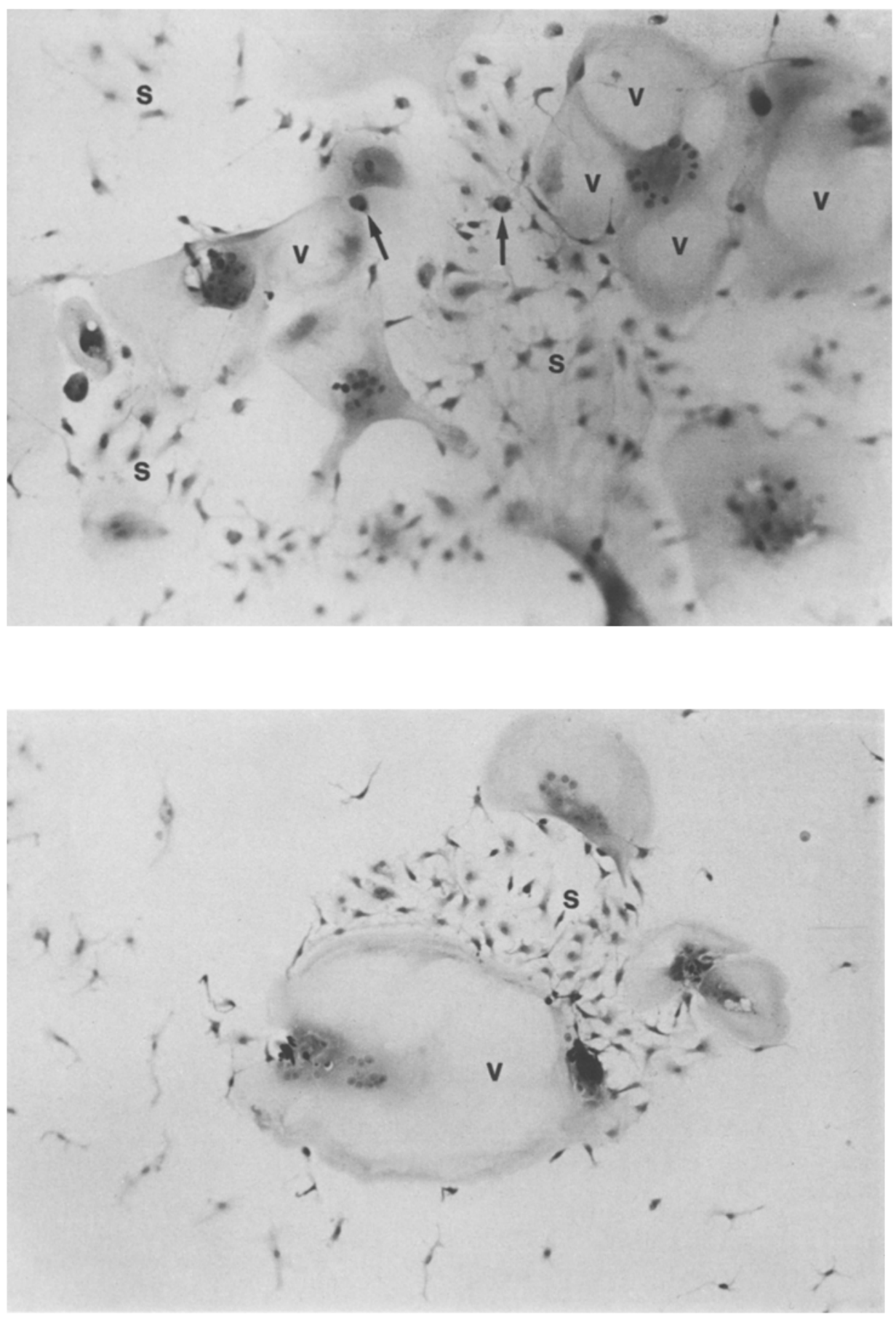

Fig. 6. Second implant exhibiting on the posterior surface of its optical zone a membrane with irregular giant cells containing diffuse protoplasmatic vacuoles $(v)$. Groups of fibroblast-like small cells $(s)$ are also seen. Two cells with larger nuclei (arrows) could be migrating corneal endothelium. Whole implant cytology technique, $\mathrm{H}$ and $\mathrm{E}$ stain, photomicrograph $\times 90$
Fig. 7. Second implant, part of the thin membrane on the front surface of the optical zone. This contains relatively few cells. Large giant cells $(g)$ contain protoplasmatic vacuoles $(v)$. Groups of fibroblast-like cells $(s)$ surround the giant cells and are distributed diffusely all over the photographed zone. Whole implant cytology technique, $\mathrm{H}$ and $\mathrm{E}$ stain, photomicrograph $\times 90$ in the protoplasm of some of the small cells. In addition to the predominant giant cells and fibroblast-like elements there were occasional epithelioid cells with large nuclei and varying pigmentation. These probably represented migrating cells from the corneal endothelium [3] or from the iris pigment epithelium.

A medallion type implant with metal loops, that had been placed successfully after extracapsular cataract extraction more than three years before, also became available for study after the eye was submitted to the Eye Bank Program. The patient was a white female 64 years old at the time of her death. This lens implant, however was removed, before the eye was fixed in formalin. The isolated implant was placed in formalin and processed for implant cytology [2]. It was totally covered with a cellophane-like membrane, that stained less eosinophilic than the membranes on the first two implants (Figs. 8 and 9). It was visible only, because it had artificial breaks at the edges of the lens and it had formed folds. The membrane in this case contained only very few giant cells in marginal areas (Fig. 8). Many small cells were distributed all through the membrane. The protoplasm of most of these cells was densely filled with pigment granules (Fig. 10). The cells were more bipolar and resembled migrated melanocytes as they may be seen on the posterior corneal surface $[4,5]$. However, some of the terminal processes of these cells were branching. 

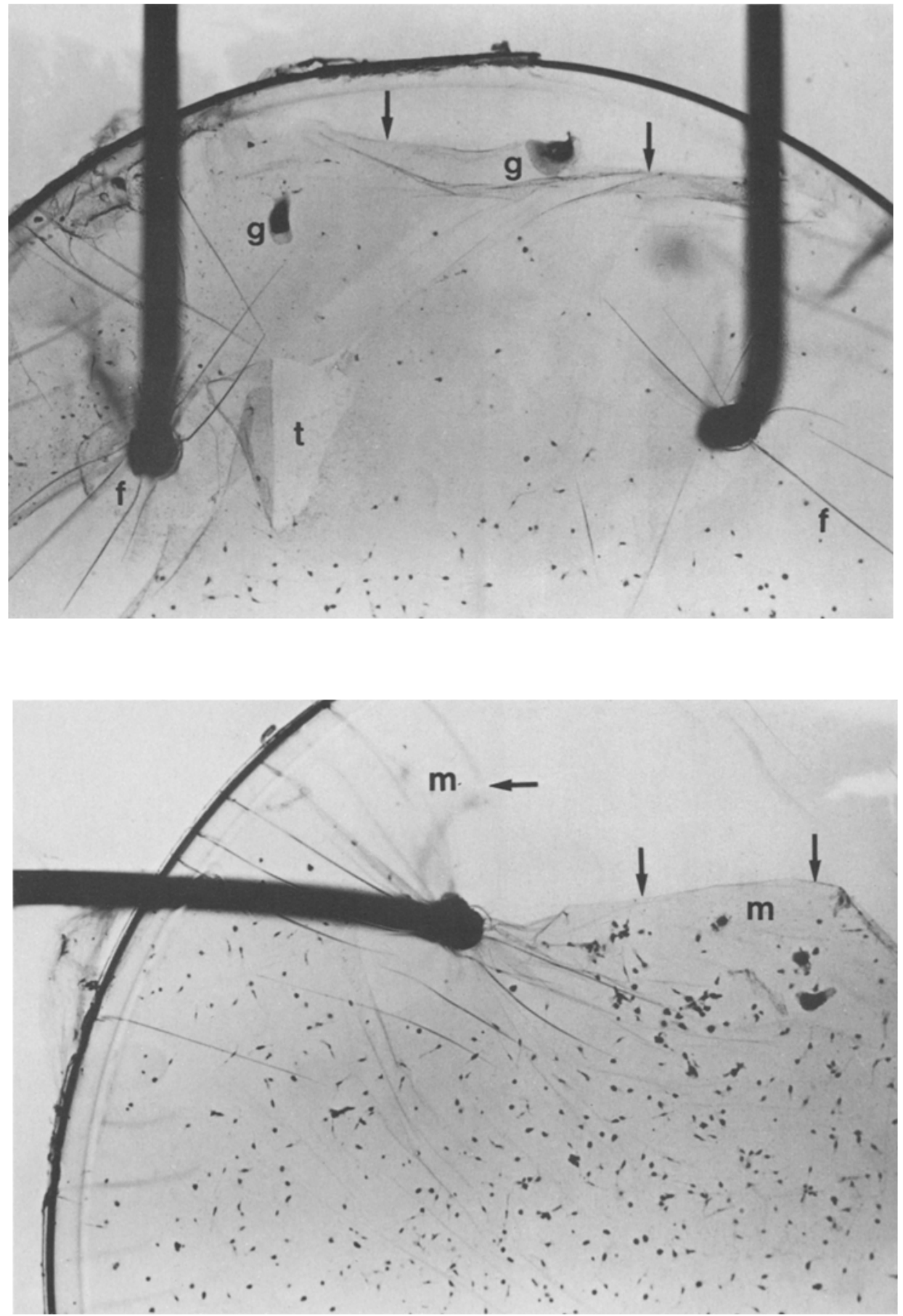

Fig. 8. Third implant with wire haptics appearing black in the photograph. Around the insertion of these haptics in the posterior lens surface, folds $(f)$ have developed in the membrane on the lens. This membrane is torn $(t)$ left to the center and along the top border of the implant (arrows). Only two giant cells $(g)$ are seen and there are numerous small cells diffusely distributed in the membrane. - Whole implant cytology technique, $\mathrm{H}$ and $\mathrm{E}$ stain, photomicrograph $\times 37,5$
Fig. 9. Third implant with partly separated (arrows) and wrinkled membrane $(m)$ on its posterior surface. The cells of this membrane are almost all small bipolar cells with pigmented protoplasm. - Whole implant cytology technique, $\mathrm{H}$ and $\mathrm{E}$ stains, photomicrograph $\times 37,5$

\section{Discussion}

The three implants reported in this study exhibit evidence for a cellular reaction and formation of a thin proteinaceous membrane on its surface. The second implant of this paper, that was removed after about one year, showed numerous foreign body cells associated with relatively few primitive fibroblast-like cell elements. The first implant obtained after two years revealed more fibroblast-like cells, fewer giant cells and a better developed membrane. The third implant, that was removed after more than 3 years, exhibited an even firmer membrane with more permanent cells. Most of these resembled melanocytes similar to those sometimes seen on the posterior corneal surface [4,
5]. There were very few giant cells. At present I believe, that the melanocytes seen on the third implant represent a later stage of the fibroblast-like cells found on the first two implants. The cytological findings on these three implants are selected for this presentation, to give a first insight into a reaction pattern, that results in the formation of a usually clear membrane on the surface of lens implants. This reaction pattern somewhat resembles typical foreign body reaction, but it has specific features. Study of a great number of different lens implants removed at different times from different conditions will soon allow for a much better understanding.

Lens implant cytology [2] is a very simple and inexpensive technique. So far, I have done the stains and the embedding 


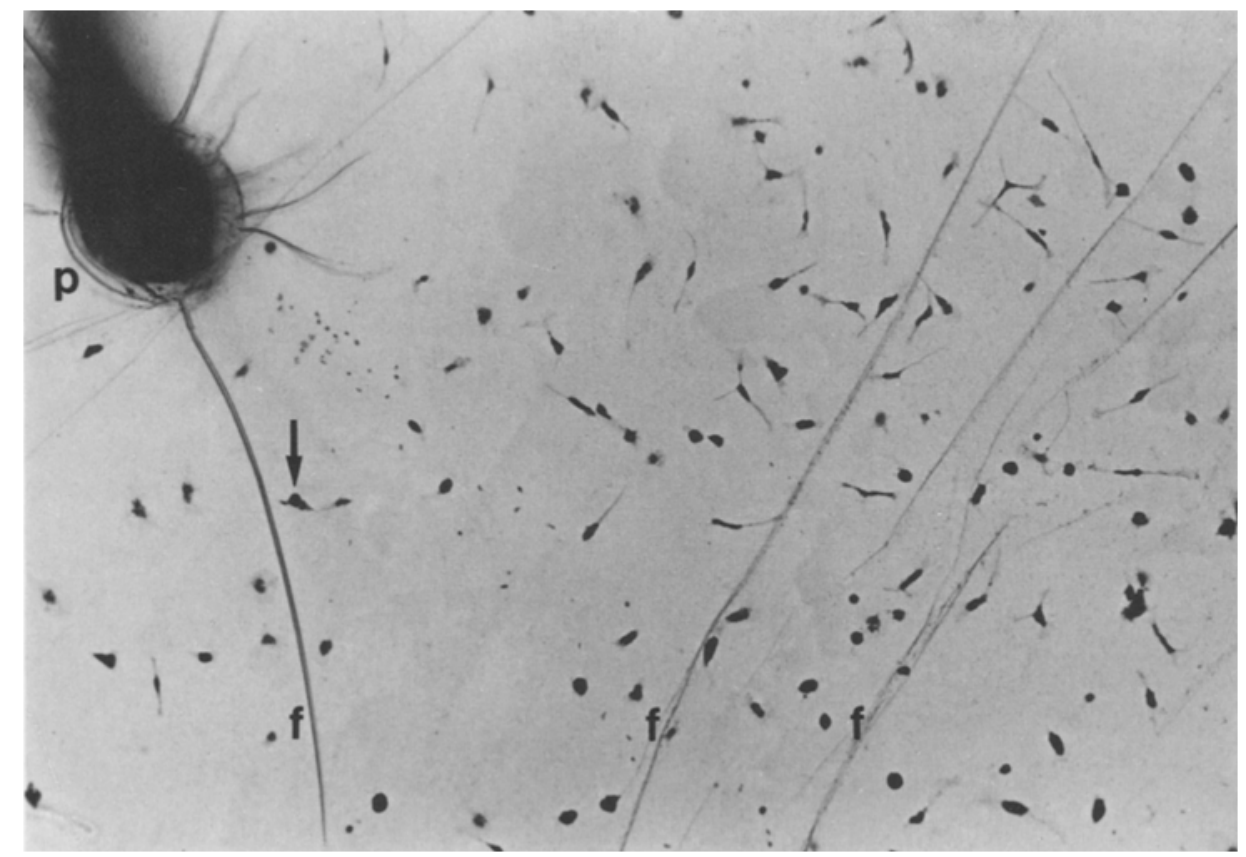

Fig. 10. Third case, higher power of an area next to the post of one metallic haptic $(p)$. Folds $(f)$ in the membrane of the lens are artifacts. All the small predominantly bipolar cells in the membrane have some pigment in their protoplasm. Some of these cells are densely filled with pigment granuoles (arrow). - Whole implant cytology technique, $\mathrm{H}$ and $\mathrm{E}$ stain, photomicrograph $\times 90$ myself and it takes me about 15 minutes. Routine HemotoxylinEosin stain allows for an excellent demonstration of the cells on all clear parts of the lens implants. Presently, I am applying special stains for better classification of cells and membrane components. It is important to recognize, that the cellular membrane on the implants is best preseved, when these are removed from living eyes at surgery or from enucleated eyes before fixation. Formalin fixation of the eye causes the membrane to stick to the tissues surrounding the implant and, thus, the membranes are often lost for implant cytology. In the long run, we should learn to isolate the membranes with the aim to study them in flat preparation. At present, the easily accessible world of implant cytology will have to be conquered and much gain of basic knowledge is expected.

\section{References}

1. Wolter JR (1960) The macrophages of the human vitreous body, Amer J Ophth, 49:99-107

2. Wolter JR, Lens implant cytology, Ophthalmic Surg, submitted

3. Sugar J, Burnett J, Forstot SL (1978) Scanning electron microscopy of intraocular lens and endothelial cell interaction, Amer J Ophth, $86: 157-161$

4. Snip RC, Green WR, Kreutzer EW, Hirst LW, Kenyon KR (1981) Posterior corneal pigmentation and fibrous proliferation by iris melanocytes, Arch Ophth, 99:1232-1238

5. Wolter JR (1981) Replacement of the corneal endothelium by melanocytes, Graefes Arch Ophth, 217:247-253

Received January 21, 1982 